\title{
Mensajes de la comunidad upoliana
}

ISSN 2308-2771

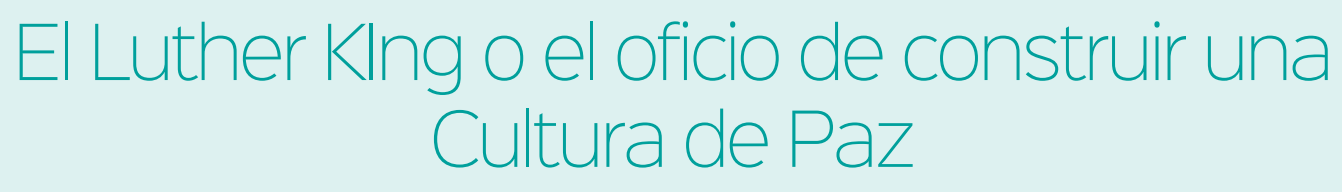

Estimados Compañeros:

Entre otras llamadas, comentarios y comunicaciones recibidas sobre el importante artículo del Asesor Presidencial para asuntos Educativos y Representante de UNESCO en Nicaragua, Dr. Miguel De Castilla, sobre el IMLK-UPOLI; nos permitimos compartir con ustedes algunos de esos hermosos mensajes:

Lunes, 3 de Octubre 2016 14:36:03

Estimado Denis:

Me es grato conocer que el prestigiado amigo y Asesor Presidencial para Asuntos Educativos y Representante de la UNESCO en Nicaragua, Dr. Miguel de Castilla Urbina, haya escrito tan elogioso artículo en El Nuevo Diario, sobre la labor del IMLK-UPOLI- Construir una Cultura de Paz a lo largo de más de veinte años, por parte del IMLK, representa un esfuerzo que solo con gran disciplina y devoción puede lograrse, y el IMLK lo ha logrado.

Sinceras felicitaciones por tan ingente labor, sigan adelante, porque la lucha para que la paz sea una realidad, requiere de mucha pasión, de mucho tesón.

Dr. Norberto Herrera

Rector Fundador UPOLI

Viernes, 30 de Septiembre 2016 21:26:50

Estimado Denis:

El Dr. Miguel De Castilla, ha publicado en El Nuevo Diario el artículo "El Luther King o el oficio de construir una Cultura de Paz". El artículo está bien cachado y creo que debemos celebrar las altas ponderaciones y los justos, meritorios y relevantes reconocimientos y elogios que hace del Instituto y de su quehacer académico, investigativo, de su luminosa trayectoria. En buena hora este calificado reconocimiento, viniendo de un probado y reconocido académico que además está en una posición cimera en las esferas políticas.

Mi más sentida congratulación para todo el Equipo extraordinario del IMLK, y de manera especial para tu persona al frente de este brillante colectivo, que la bendición del Señor continúe con el Equipo del Martín Luther King. Dr. Sergio Denis García Rector Emérito UPOLI

Lunes, 3 de Noviembre 2014 12:30:10

Estimado Maestro Torres,

Acuso recibo de la nota en torno al texto de presentación del Dr. Miguel De Castilla, de la obra La Rama de Olivo. Una Cultura de Paz Global.

Mis felicitaciones para usted y todo el equipo de trabajo del IMLK por la producción intelectual muy importante para el fortalecimiento de la Cultura de Paz.

Con aprecio,

Dra. Lidya Zamora, PhD

Rectora

Viernes, 30 de Septiembre 2016 11:21:28

Estimados amigos del IMLK, os felicito por la resonancia que tiene el Instituto, reconocido como uno de los más destacados instrumentos de extensión de la UPOLI.

Dr. Raül i Morel

Consultor UPOLI

Lunes, 3 de Octubre 2016 11:37:32

Hola Soren, ¿cómo le va?

Felicidades por lo escrito por el Dr. Miguel De Castilla, es muy bonito y pertinente todo lo que menciona, me parece que es digno de elogiar la labor que tienen ustedes, no solamente dentro de la Universidad, sino también fuera de ella.

Así que adelante, la animo a seguir trabajando así de bien como lo han hecho, y espero que el sábado haya avanzado bastante, siempre tenemos que hacer sacrificios verdad? todo sea por el bienestar nuestro y de la Institución que es nuestra segunda casa.

Un abrazo le envió desde la oficina hermana: Áreas Básicas.

MSc. Indira Hernández Lagos Coordinadora CCSS/Áreas Básicas 
Estimado hermano Denis Torres:

He leído con mucho gozo, el escrito del Asesor Presidencial para Asuntos Educativos y representante de la UNESCO en Nicaragua, Dr. Miguel De Castilla, referente a la presentación del IMLK (por motivo de la celebración del "Día Internacional de la Paz", en la Sala "Pablo Antonio Cuadra" de Hispamer), del libro La Rama de Olivo, Una Cultura de Paz Global. En dicho escrito, el Asesor Presidencial ubica al IMLK como el único organismo de carácter académico EN NICARAGUA, y probablemente de la región, cuya misión institucional de investigación -docencia y extensión sea la PAZ.Ese posicionamiento al que se refiere el Dr. Miguel De Castilla del IMLK, enaltece y "dota" a la UPOLI como una universidad comprometida con la tan deseada PAZ, no solamente para la región latinoamericana, sino que con la PAZ MUNDIAL.....una vez más, muchas felicitaciones para usted y resto del personal del IMLK.

Muchas felicidades a usted, a nuestro estimado y siempre recordado Rev. José Miguel Torres (q.e.p.d) y resto del personal del Instituto Martín Luther King.

\section{MSc. Harold García}

Educación Continua

UPOLI

\section{MSc. Denis Torres \\ Director Instituto Martin Luther King UPOLI}

Reciba un cordial saludo.

Mis felicitaciones a su persona y a todo el equipo de colaboradores del Instituto Martin Luther King, por este importante reconocimiento de la labor que realizan día a día, el profeta Isaías en el capítulo 52, verso 7, inspirado por nuestro Dios expresa: ¡Cuán hermosos son sobre los montes los pies del que trae alegres nuevas, del que anuncia la paz, (C) del que trae nuevas del bien, del que publica salvación, del que dice a Sion: ¡Tu Dios reina!

Ese es el legado que recibimos de nuestro Señor Jesucristo, que Dios le continúe bendiciendo, dándole ese ánimo para seguir proclamando la paz en medio de un mundo donde hay mucha violencia y maldad.

Bendición de lo alto.

Víctor Rodríguez Oficina de cobranza UPOLI RUR Rivas

\section{IMLK: Contribuyendo a la paz en Irak}

\author{
Universidad de Sulaymaniyah en Irak \\ Del 17 al 21 de octubre, 2016 \\ Martes, 11 de Octubre 2016 11:47:30
}

Estimado Denis.

Muy regocijado por la participación de la UPOLI, a través del IMLK, en la Conferencia Internacional de la Universidad de Irak, según compartes en tu comunicación. La temática es relevante y la ponencia de Ustedes, muy pertinente. Les felicito y felicito a la UPOLI y al Instituto que goza de tu liderazgo. Mis oraciones, aprecio solidario para Soren.

Me siento orgulloso en el relevo generacional que nos sigue. Ha valido la pena lo andado, sabiendo que las banderas quedan en manos muy valiosas, como las de Soren. Y como ella, hay otros y otras creciendo en las Escuelas, Institutos y Sedes o RUR. Es una digna representante de la UPOLI. Desde ese Instituto (IMLK), porta su identidad y vive el proyecto institucional de la UPOLI.

He tenido oportunidad de compartir con ella, en el proceso de la Estrategia VI del PEI UPOLI y he logrado aquilatar lo que escribo. Dios les bendiga.

MSc. Francisco José Mendoza Darce Director en funciones del ICIDRI
Martes, 11 de Octubre 2016 16:38:56

Estimado hermano Denis.

Ante todo saludos a Ud., extensivos a su muy eficiente colectivo de trabajo, que le apoya de manera incondicional, en las importantes tareas de ese prestigioso Instituto que Ud. dirige, dignamente.

Hace días que estoy pendiente de dejar constancia gráfica de mi agradecimiento a sus palabras de elogio al trabajo del Conservatorio, que nos halagan, pero que también nos comprometen más, ante nuestras autoridades y la comunidad upoliana en general.

Solo me resta decirle, al respecto que nosotros trabajamos acá, como si cada una de nuestras tareas y funciones fueran "....para el Señor....", mandato bíblico, que cumplimos, por lo cual consideramos que es nuestro deber actuar así.....

En cuanto esa fecha tan significativa para el mundo y muy especialmente para la UPOLI, pues hace exactamente veinte años la UNESCO le otorgó la medalla Mahatma Gandhi de la Tolerancia al Instituto Martin Luther King, en la persona de su Director, Denis Torres, y a la UPOLI, en la 
persona de su Rector, Sergio Denis García, ocasión en que, por primera vez, desde el inicio de mi Misión, el Conservatorio tuvo una participación artística, para el respetable público presente, tales como nuestras autoridades de entonces, incluyendo la distinguida visita del Dr. Federico Mayor Zaragoza, entonces Director General de la UNESCO.

Fue ese día histórico para mi vida, pues comencé a aprender el significado de la palabra PAZ, que para mí hasta allí, era solamente "...la ausencia de Guerra..." Mucho ha tenido que ver ese Instituto bajo su acertada dirección y muy especialmente, su hermano José Miguel, ya con el Señor, con quien año con año, organicé cada actividad que se realizó cada septiembre.

Entonces, mi estimado hermano Denis, yo soy la más agradecida de ustedes, de la obra que con afán y pasión ustedes realizan para el entendimiento de su Misión que cada vez más resalta en el universo no solo en Nicaragua, sino también allende los mares, manifiesto con muchas acciones y reconocimientos, especialmente con esta última Distinción en la persona de esa destacada miembro de su excelente equipo de trabajo, Soren, que expondrá hasta su vida con esa arriesgada Invitación, pero, seguramente ella estará bajo el Manto Divino de Dios, que cuidará de su sierva, como lo hace con sus hijos....

Que el buen Dios les continúe bendiciendo y usando con poder es mi deseo y oración.

Siempre fraterna, en Cristo, su hermana,

María Caridad

Directora Conservatorio de Música/ UPOLI

Managua, 12 de octubre de 2016

Lic. Denis Torres

Director en funciones del IMLK

UPOLI

Estimado Director:

En nombre de la Dirección de Áreas Básicas queremos dejar patentizado que la participación de la UPOLI, a través de Soren Chamorro en una Conferencia de tal magnitud en la Universidad de Irak, es importante y necesaria ante lo que se está viviendo en el mundo. Sin duda alguna Soren hará un buen trabajo y la UPOLI estará muy bien representada. La temática es relevante y pertinente en este contexto. liderazgo.
La DAB está muy contenta por la selección de quien los representará. Ella es digna representante de la UPOLI y del Instituto.

Bendiciones para todos y adelante ante esos nuevos desafíos.

Mtra. Fátima Alemán

Directora de Áreas Básicas

UPOLI, Sede Central.

Jueves, 13 de Octubre 2016 9:55:45

Asunto: Re: IMLK-UPOLI en Irak

Estimado Licenciado

Denis Torres

Director

IMLK-UPOLI

Me uno al regocijo de los que queremos a esta amada Universidad Politécnica de Nicaragua, UPOLI... porque Dios en su gran misericordia y amor que tiene para esta Institución, que es DEL SEÑOR, esté dando fructíferos frutos para intentar lograr la tan anhelada PAZ MUNDIAL, a través y por medio del Instituto Martín Luther King de la UPOLI.

Nos llena de mucha alegría Cristiana al saber que la compañera Soren Chamorro viajará a IRAK, invitada por una Universidad para disertar en la Conferencia Internacional con el tema: Reconstrucción de sociedades en guerra, continuidad y nuevos inicios y lo más importante "sobre la experiencia nicaragüense de reconversión de las fuerzas armadas en el Post-conflicto bélico" ........ Esto enorgullece a la UPOLI y la trasciende a otros niveles para ser considerada como una universidad Latinoamericana abanderada en la lucha POR LOGRAR LA PAZ.

Hermano Denis, tenga la plena seguridad que nuestra oraciones estarán dirigidas a que la disertación que hará la compañera Soren Chamorro, redunde en gran beneficio y pueda ser oída por toda esa región que lamentablemente viven en conflictos bélicos, para la posibilidad de que también ellos puedan gozar de la paz que gozamos en nuestra amada Nicaragua.

Reciba usted y resto del equipo de la IMLK las muestras de mi mayor consideración.

MSc. Harold García EDUCON 